ARTICLE

\title{
Inorganic-organic competitive coating strategy derived uniform hollow gradient-structured ferroferric oxide-carbon nanospheres for ultra-fast and long-term lithium-ion battery
}

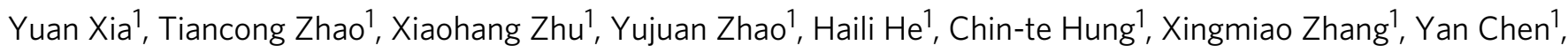
Xinlei Tang ${ }^{1}$, Jinxiu Wang ${ }^{1}$, Wei Li (i) ${ }^{1 \times} \&$ Dongyuan Zhao (iD ${ }^{1 凶}$

The gradient-structure is ideal nanostructure for conversion-type anodes with drastic volume change. Here, we demonstrate an inorganic-organic competitive coating strategy for constructing gradient-structured ferroferric oxide-carbon nanospheres, in which the deposition of ferroferric oxide nanoparticles and polymerization of carbonaceous species are competitive and well controlled by the reaction thermodynamics. The synthesized gradient-structure with a uniform size of $\sim 420 \mathrm{~nm}$ consists of the ferroferric oxide nanoparticles (4-8 nm) in carbon matrix, which are aggregated into the inner layer $(\sim 15 \mathrm{~nm})$ with high-to-low component distribution from inside to out, and an amorphous carbon layer $(20 \mathrm{~nm})$. As an anode material, the volume change of the gradient-structured ferroferric oxide-carbon nanospheres can be limited to $\sim 22 \%$ with $\sim 7 \%$ radial expansion, thus resulting in stable reversible specific capacities of $\sim 750 \mathrm{mAh}^{-1}$ after ultra-long cycling of 10,000 cycles under ultra-fast rate of $10 \mathrm{Ag}^{-1}$. This unique inorganic-organic competitive coating strategy bring inspiration for nanostructure design of functional materials in energy storage.

\footnotetext{
${ }^{1}$ Department of Chemistry, Shanghai Key Lab of Molecular Catalysis and Innovative Materials, and Laboratory of Advanced Materials, Fudan University, Shanghai, P. R. China. ${ }^{\bowtie}$ email: weilichem@fudan.edu.cn; dyzhao@fudan.edu.cn
} 
$\mathrm{R}$ echargeable lithium-ion batteries (LIBs) have been recognized as the most important power supply for portable electronics and electric vehicles ${ }^{1-3}$. Recently, there is an ever-growing demand to develop next-generation LIBs with high energy density, long cycling life, and low cost ${ }^{4-6}$. The key issue is creating high-capacity and ultra-stable electrode materials. In this regard, transition metal oxides and silicon have been regarded as the most promising candidates for the next-generation LIBs because of their high theoretical capacities ${ }^{7-10}$. Nevertheless, the increased specific capacity is generally accompanied by many challenges based on their conversion-type lithium-storage mechanism, such as large volume change ${ }^{11-13}$, and low electronic/ionic conductivity ${ }^{14-16}$. Actually, the drastic volume changes are more lethal than other problems in the case of fast charging and discharging, which leads to unstable solid-electrolyte interphase (SEI) film, severe electrode pulverization, and loss of electrical contact, consequently, thus resulting in rapid capacity fading and even the safety problem of the battery 17,18 .

Over the past decade, various nanostructure designs have been proposed to tackle the problems associated with the transition metal oxides and silicon anodes ${ }^{19-25}$. Reducing the active material size from the micrometer to the nanoscale regime is the most direct strategy to relieve the stress caused by volume change. In fact, a wide range of nanostructures have been developed and intensively investigated such as nanoparticles ${ }^{26,27}, 1 \mathrm{D}$ nanorods/ nanowires $28,29,2 \mathrm{D}$ nanosheets ${ }^{30,31}$, porous structures $^{32-34}$, hollow $^{35,36}$ and hierarchical structures ${ }^{37-39}$. But the nanostructuring active materials inevitably increases the electrodeelectrolyte contact area, thus, increases the dissolution and formation of SEI film, resulting in a low Coulombic efficiency and poor cycle life. Surface modification to form core-shell structures is a useful strategy for stabilizing SEI film by minimizing the electrode/electrolyte interfacial side reaction, increasing the electronic conductivity, and thus improving the lifetime of active materials ${ }^{40-42}$. Unfortunately, it is greatly challenging to construct a stable coating layer to retain the SEI film because the huge volume change of active cores is associated with $\mathrm{Li}^{+}$-ion insertion/extraction process. The promising strategy to address this issue is to reserve space for volume change to form yolk-shell structure, in which the interior void space buffers the drastic volume change without cracking the overall electrode, and the outer shells can help to stabilize the SEI film. Nevertheless, in this kind of structures, the active cores are generally movable and vulnerable, making it difficult to achieve robust electronic connections and protective effect with the outer conductive shells, furthermore, the yolk void spaces could not be fully utilized during the large volume expansion and change, as a result, leading to unsatisfactory rate and cycling performances. Despite progresses have been achieved, it remains great challenge to develop a reasonable structure for substantially improving the battery performance to an ultrafast and long-life level. Gradientstructure, in which the active and modified materials combine in a sufficient contact way at the nanoscale, can drastically increase interaction areas, gradually release the stress caused by the volume change, therefore is an ideal structure for improving the stability of electrodes during ultrafast charging and discharging. However, constructing such gradient-structure has not been successful yet until now because it is difficult to control gradient component distribution by variable deposition reaction between different materials.

Herein, inspired by the structure of coconut, we design a hollow gradient-structured ferroferric oxide-carbon (HG$\left.\mathrm{Fe}_{3} \mathrm{O}_{4} @ \mathrm{C}\right)$ nanospheres for ultrafast, long-term lithium-ion battery anodes. Using metallorganic compound ferrocene as the sole source for carbon and iron, we demonstrate a unique inorganic-organic competitive coating strategy for constructing a uniform gradient-structured $\mathrm{Fe}_{3} \mathrm{O}_{4} @ \mathrm{C}$ shell on the surface of colloidal silica nanospheres, in which the deposition of $\mathrm{Fe}_{3} \mathrm{O}_{4}$ nanoparticles and polymeric carbonaceous species are competing gradually and well-controlled by the reaction thermodynamics. After removal of the silica spherical cores, the as-obtained nanospheres show a unique hollow gradient-structure with highly uniform particle size of $\sim 420 \mathrm{~nm}$. Where the $\mathrm{Fe}_{3} \mathrm{O}_{4}$ nanoparticles (4-8 $\mathrm{nm})$ conformably coated by ultrathin conductive graphitic carbon are aggregated into the inner layer of carbonaceous matrix with high-to-low component distribution from inside to out (15 $\mathrm{nm})$, which is encapsulated by an amorphous carbon layer $(\sim 20$ $\mathrm{nm}$ in thickness). When being used as anodes for lithium-ion storage, the as-obtained uniform gradient-structured $\mathrm{Fe}_{3} \mathrm{O}_{4} @ \mathrm{C}$ nanospheres deliver an impressive reversible capacity of $\sim 750$ $\mathrm{mAh} \mathrm{g}^{-1}$ with a Coulombic efficiency as high as $\sim 99.0 \%$ even after 10,000 cycles at a high current density of $10 \mathrm{~A} \mathrm{~g}^{-1}$, which is immensely higher than that of yolk-shell structured $\mathrm{Fe}_{3} \mathrm{O}_{4} @ \mathrm{C}$ (350 $\mathrm{mAh}^{-1}$ ) and hollow hybrid structured $\mathrm{Fe}_{3} \mathrm{O}_{4} @ \mathrm{C}$ (330 $\mathrm{mAh} \mathrm{g}^{-1}$ ) nanospheres. Even at an ultrafast rate of $20 \mathrm{Ag}^{-1}$, significantly high capacities of $\sim 500 \mathrm{mAh} \mathrm{g}^{-1}$ can be retained after 10,000 cycles. We believe that the unique inorganic-organic competitive strategy is easy, reproducible, general, and can bring inspiration for nanostructuring and composites design of nextgeneration high-performance anodes.

\section{Results}

Morphological and structural characterization. The synthesis procedure of the hollow gradient-structured $\mathrm{Fe}_{3} \mathrm{O}_{4} @ \mathrm{C}$ nanospheres is illustrated through the inorganic-organic competitive coating strategy (Fig. 1). In this synthesis, ferrocene, a metallorganic compound, is used as the sole source both for carbon and iron to directly coat $\mathrm{Fe}_{3} \mathrm{O}_{4} @ \mathrm{C}$ shells on the surface of colloidal silica nanospheres. Then, a high-to-low gradient $\mathrm{Fe}_{3} \mathrm{O}_{4} @ \mathrm{C}$ component distribution can be obtained via a simple solvothermal process. Field-emission scanning electron microscopy (FESEM) images show that the as-made core-shell nanospheres are highly uniform with a diameter of $\sim 420 \mathrm{~nm}$ (Supplementary Fig. 1). Compared with that for the initial colloidal silica cores $(\sim 350$ $\mathrm{nm})$, the diameter of the gradient-structured nanospheres increases, clearly indicating that the coating thickness is about 70 $\mathrm{nm}$. After the calcination and selective removal of the silica cores, the obtained hollow gradient $\mathrm{Fe}_{3} \mathrm{O}_{4} @ \mathrm{C}$ nanospheres with an inner void of $\sim 350 \mathrm{~nm}$ show monodispersed size distribution of $\sim 420 \mathrm{~nm}$ with inconspicuous shrinking (Fig. 2A-E). The magnified TEM images of a single $\mathrm{Fe}_{3} \mathrm{O}_{4} @ \mathrm{C}$ nanosphere disclose the unique gradient-structure (Fig. $2 \mathrm{D}, \mathrm{E}$ ). Where the $\mathrm{Fe}_{3} \mathrm{O}_{4}$ nanoparticles (4-8 nm in size) in carbonaceous matrix are aggregated into the inner layer with high-to-low component distribution from inside to out, which is encapsulated by an outer amorphous carbon layer $(\sim 20 \mathrm{~nm})$ without $\mathrm{Fe}_{3} \mathrm{O}_{4}$. The hollow structure can also be confirmed by the scanning electron microscope (SEM) images of a broken nanosphere (Fig. 2C). High-resolution TEM (HRTEM) images demonstrate that the $\mathrm{Fe}_{3} \mathrm{O}_{4}$ nanoparticles in the inner mesoporous layer are highly crystallized with a relatively uniform particle size of $4-8 \mathrm{~nm}$ and conformably wrapped by few graphitic carbon layers (Fig. 2F and Supplementary Fig. 2). Moreover, bright voids can be clearly observed between the $\mathrm{Fe}_{3} \mathrm{O}_{4}$ nanoparticles, which are the characteristic of mesoporous structures. Selective etching method is used to further confirm the gradient-structure of the obtained nanospheres. After etching by $\mathrm{HF}$ solution to remove the $\mathrm{Fe}_{3} \mathrm{O}_{4}$ nanoparticles from the carbonaceous matrix, the inner surface of the obtained hollow carbon nanospheres is pitted with craters (Supplementary Fig. 3), clearly indicating that the $\mathrm{Fe}_{3} \mathrm{O}_{4}$ nanoparticles are gradient-embedded in the inner wall of amorphous carbon layers. In contrast, when 


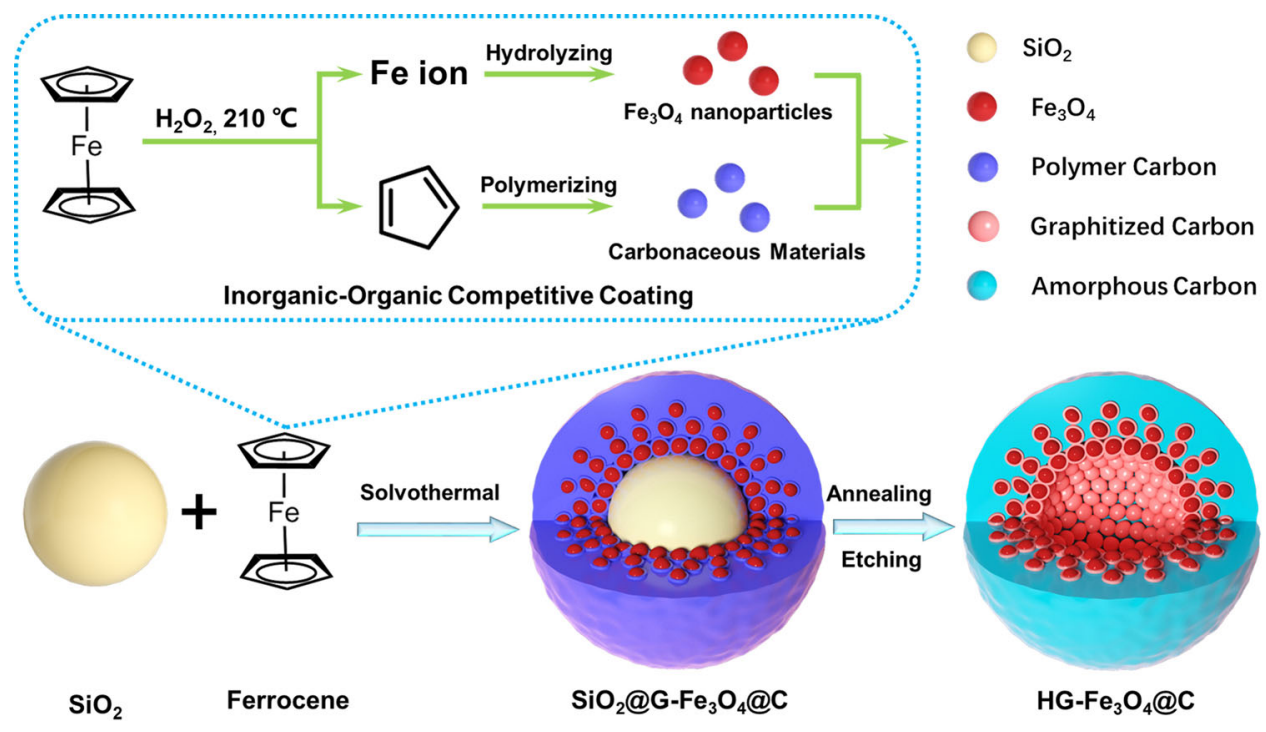

Fig. 1 Schematic diagram for the synthesis of the hollow gradient-structured $\mathrm{Fe}_{3} \mathrm{O}_{4} @ \mathrm{C}$ nanospheres via an inorganic-organic competitive coating strategy. The colloidal $\mathrm{SiO}_{2}$ nanospheres can be used as a sacrificial template for the hollow structure. Metallorganic compound, Ferrocene is selected as a sole source for both iron and carbon.

etching the as-made $\mathrm{SiO}_{2} @ \mathrm{Fe}_{3} \mathrm{O}_{4} @ \mathrm{C}$ nanospheres with $1.0 \mathrm{M}$ $\mathrm{NaOH}$ to remove the polymeric carbonaceous layers or matrixes, the hollow hybrid $\mathrm{Fe}_{3} \mathrm{O}_{4} / \mathrm{C}$ nanospheres without thick carbon outer layer can be obtained, which further proves the gradient distribution of carbon and $\mathrm{Fe}_{3} \mathrm{O}_{4}$ nanoparticles in the nanospheres (Supplementary Fig. 4). The selected-area electron diffraction (SAED) characterization reveals the high crystallization of $\mathrm{Fe}_{3} \mathrm{O}_{4}$ nanoparticles in the hollow gradient-structure (Fig. 2G). The scanning TEM (STEM) and corresponding EDS mapping images show that the hollow profiles of Fe element are well coincided with $\mathrm{O}$ but smaller than that of $\mathrm{C}$, indicating that the gradient distribution $\mathrm{Fe}_{3} \mathrm{O}_{4}$ nanoparticles is encapsulated by an outer amorphous carbon layer (Fig. $2 \mathrm{H}-\mathrm{K}$ ). From the in situ TEM characterization based on the electron tomography and spinning projection technology (Video 1 and 2), it is further demonstrated that the distinct gradient embedment of $\mathrm{Fe}_{3} \mathrm{O}_{4}$ nanoparticles within the carbon shells, and the unique "occlusion"-like schemes between the two materials.

$\mathrm{X}$-ray diffraction (XRD) patterns (Supplementary Fig. 5A) of the gradient-structured $\mathrm{Fe}_{3} \mathrm{O}_{4} @ \mathrm{C}$ nanospheres show that all diffraction peaks can be well assigned to pure magnetite $\mathrm{Fe}_{3} \mathrm{O}_{4}$ (JCPDS card no.11-0614). The average crystallite sizes of the $\mathrm{Fe}_{3} \mathrm{O}_{4}$ can be calculated to $\sim 5.3 \mathrm{~nm}$ by Debye-Scherrer formula. This value is well-matched with the TEM data of $(4-8 \mathrm{~nm})$. The G band of the carbon in the Raman spectra (Supplementary Fig. 5B) shift to a higher wave number of $1613 \mathrm{~cm}^{-1}$ compared with that of the graphite single crystal $\left(1575 \mathrm{~cm}^{-1}\right)$, indicating that a large amount of disordered graphite-like carbon in the gradientstructured $\mathrm{Fe}_{3} \mathrm{O}_{4} @ \mathrm{C}$ nanospheres. The carbon content in the gradient-structured $\mathrm{Fe}_{3} \mathrm{O}_{4} @ \mathrm{C}$ nanospheres can be estimated to be about 23.8\% based on the TGA data (Supplementary Figs. 5C, 6, 7). The $\mathrm{N}_{2}$ adsorption/desorption isotherms of the gradientstructured $\mathrm{Fe}_{3} \mathrm{O}_{4} @ \mathrm{C}$ nanospheres show a typical type III feature (Supplementary Fig. 5D), indicating the microporosity of this mesoporous structure aggregated by nanoparticles is nonsignificant. The micropore volumes determined from $\mathrm{N}_{2}$ adsorption and $\mathrm{CO}_{2}$ adsorption (Supplementary Fig. 5E) are 0.005 and $0.007 \mathrm{~cm}^{3} \mathrm{~g}^{-1}$, respectively, being negligible compared with the total pore volume $\left(0.32 \mathrm{~cm}^{3} \mathrm{~g}^{-1}\right)$. The BET surface area of the gradient-structured $\mathrm{Fe}_{3} \mathrm{O}_{4} @ \mathrm{C}$ nanospheres is about $141 \mathrm{~m}^{2} \mathrm{~g}^{-1}$. Pore size distribution obtained from Barrett-Joyner-Halenda model indicates the presence of mesopore with pore size at around $4 \mathrm{~nm}$ (Supplementary Fig. 5F).

The formation process of gradient-structures and its versatility. The temperature- and time-dependent experiments were carried out to examine the deposition of $\mathrm{Fe}_{3} \mathrm{O}_{4}$ and amorphous carbonaceous (Supplementary Figs. 8, 9). When the reaction temperature is set as $180^{\circ} \mathrm{C}$, a pure carbon layer without visible $\mathrm{Fe}_{3} \mathrm{O}_{4}$ nanoparticles is coated on the surface of the colloid $\mathrm{SiO}_{2}$ nanospheres (Supplementary Fig. 8A, E, I). Corresponding XRD pattern further confirms that the $\mathrm{Fe}_{3} \mathrm{O}_{4}$ nanoparticles cannot be formed at such low temperature (Supplementary Fig. 8M). Increasing the reaction temperature to $190^{\circ} \mathrm{C}, \mathrm{Fe}_{3} \mathrm{O}_{4}$ nanoparticles can be observed in a form of aggregations, which adhere to the surface of a pure carbon layer (Supplementary Fig. 8B, F, J). Interestingly, when the temperature increases to $200^{\circ} \mathrm{C}$, the $\mathrm{Fe}_{3} \mathrm{O}_{4}$ nanoparticles are embedded in carbonaceous matrix at the inner of the coating-layer to form a gradient high-to-low component distribution from inside to out (Supplementary Fig. 8C, G, $\mathrm{K})$. Further increasing the reaction temperature, $\mathrm{Fe}_{3} \mathrm{O}_{4}$ nanoparticles are locally concentrated at the inner walls of the coatinglayer, and no $\mathrm{Fe}_{3} \mathrm{O}_{4}$ particles can be observed within the outer carbon walls (Supplementary Fig. 8D, H, L). In this case, it can clearly be seen that at the beginning of deposition process, the $\mathrm{Fe}_{3} \mathrm{O}_{4}$ nanoparticles covered by ultrathin carbon layers are rapidly deposited on the colloid $\mathrm{SiO}_{2}$ cores (Supplementary Fig. 9A, B). With the reaction, the thickness of the $\mathrm{Fe}_{3} \mathrm{O}_{4}$-rich layers is increased, which is then encapsulated by an out carbon wall after $24 \mathrm{~h}$ (Supplementary Fig. 9C, D). XRD patterns show that the diffraction intensities of the magnetite nanoparticles increase with the reaction temperature, suggesting that the deposition of $\mathrm{Fe}_{3} \mathrm{O}_{4}$ nanoparticles is determined on thermodynamics (Supplementary Fig. 8M). From another point of view, the carbon layers with a similar thickness can be formed from 180 to $210^{\circ} \mathrm{C}$, indicating that the coating rate slightly increases at the controlled temperatures (Supplementary Fig. 10).

It is worth noting that our inorganic-organic competitive coating strategy is simple and versatile to synthesize uniform gradient-structured $\mathrm{Fe}_{3} \mathrm{O}_{4} @ \mathrm{C}$ nanospheres with controllable particle size from 150 to $500 \mathrm{~nm}$ and shell thicknesses ranging 

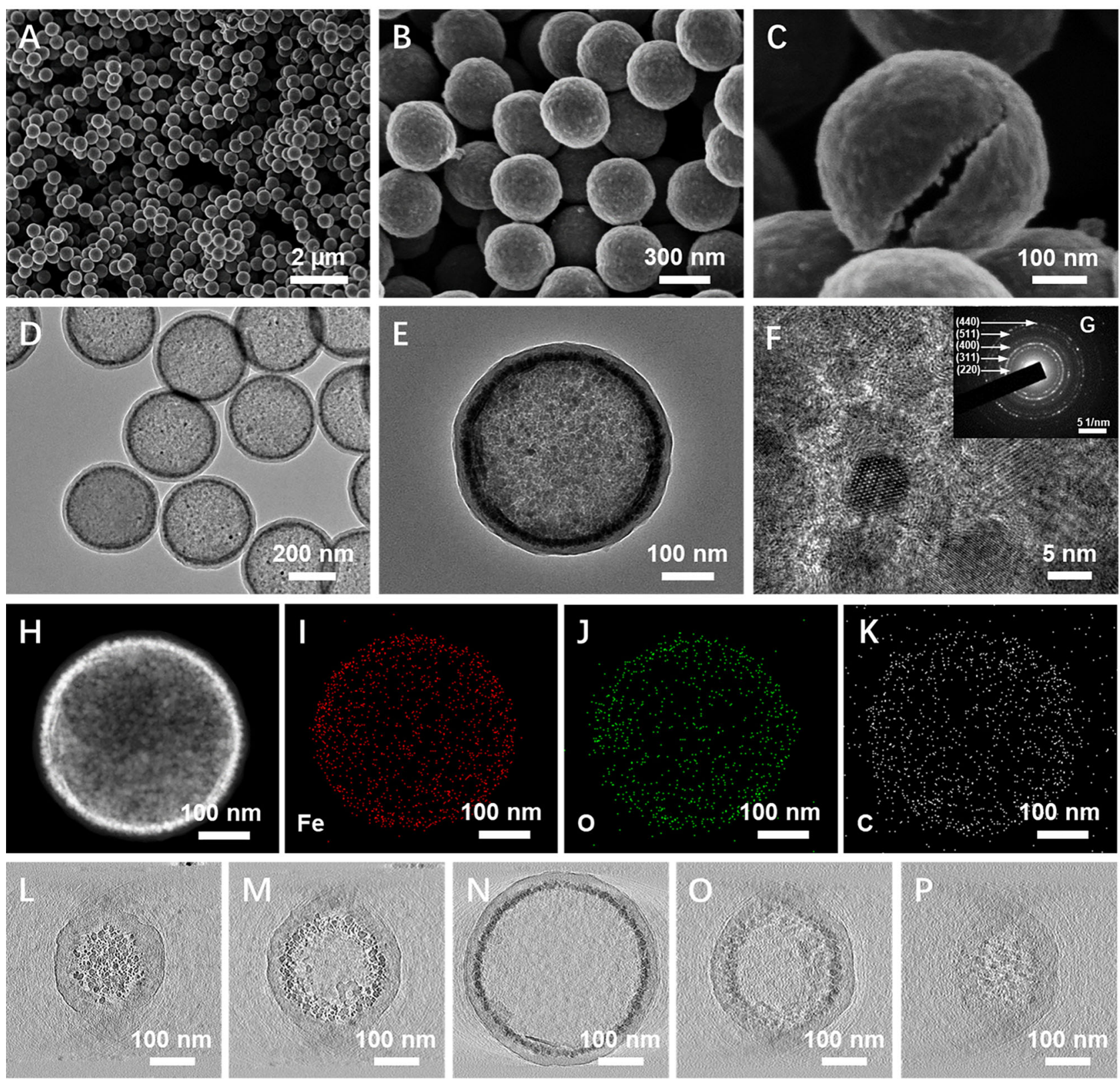

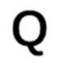

$\mathbf{R}$

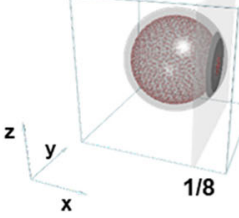

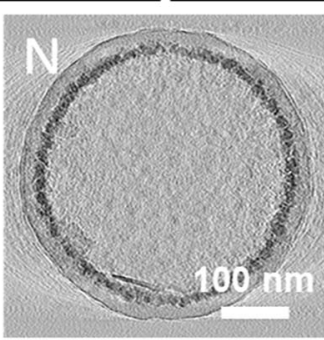

$\mathrm{S}$

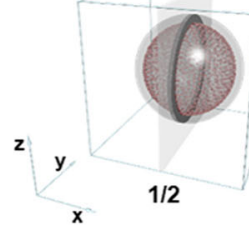

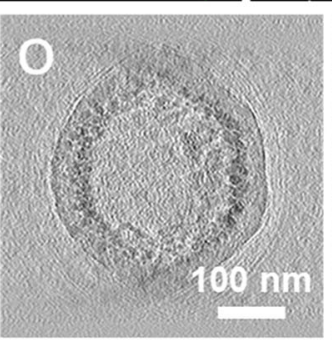

T

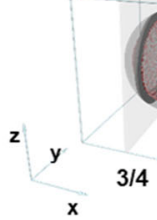

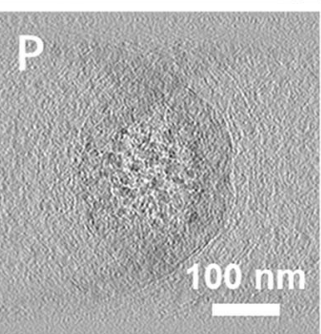

$\mathrm{U}$

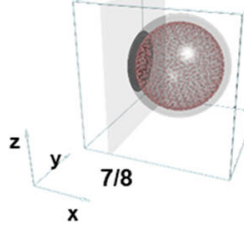

Fig. 2 Morphology characterization of the hollow gradient-structured $\mathbf{F e}_{\mathbf{3}} \mathbf{O}_{\mathbf{4}} @ \mathbf{C}$ nanospheres. A, B, C SEM and D, E TEM images of the gradientstructured $\mathrm{Fe}_{3} \mathrm{O}_{4} @ \mathrm{C}$ nanospheres; $\mathbf{F}$ HRTEM image of the gradient-structured $\mathrm{Fe}_{3} \mathrm{O}_{4} @ \mathrm{C}$ nanospheres; The inset in (F) is the selective area electronic diffraction (SAED) pattern (G) of the sample gradient-structured $\mathrm{Fe}_{3} \mathrm{O}_{4} @ \mathbf{C}$ nanospheres; $\mathbf{H} \mathrm{STEM}$, and $\mathbf{I}, \mathbf{J}, \mathbf{K}$ corresponding EDS mapping of Fe, $\mathrm{O}$, and $\mathrm{C}$ elements distribution in the typical nanosphere; L-P TEM images of different slice depths of the sample gradient-structured $\mathrm{Fe}_{3} \mathrm{O}_{4} @ \mathbf{C}$ nanosphere and $\mathbf{Q}-\mathbf{U}$ corresponding section schematic.

from 20 to $80 \mathrm{~nm}$ (Supplementary Figs. 11, 12). More interestingly, when the concentration of colloidal silica nanospheres increases four times, the nucleated $\mathrm{Fe}_{3} \mathrm{O}_{4}$ nanocrystals are not enough to cover the whole surface of the templates. Thus, a strawberry-like growth of gradient-structured $\mathrm{Fe}_{3} \mathrm{O}_{4} @ \mathrm{C}$ shells can be obtained (Supplementary Figs. 13, 14), further indicating that the inorganic-organic competitive and interface-induced deposition process. Moreover, this competitive coating strategy is versatile, various functional cores, such as core-shell $\mathrm{Fe}_{3} \mathrm{O}_{4} @ \mathrm{SiO}_{2}$ nanospheres and core-shell $\mathrm{SiO}_{2} @ \mathrm{G}-\mathrm{Fe}_{3} \mathrm{O}_{4} @ \mathrm{C}\left(\mathrm{SiO}_{2}\right.$ coated by gradient-structured $\mathrm{Fe}_{3} \mathrm{O}_{4} @ \mathrm{C}$ layer) nanospheres, can be obtained with hollow structures, leading to the formation of 
A

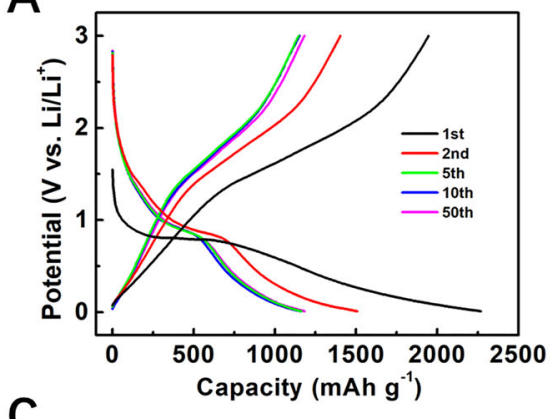

C

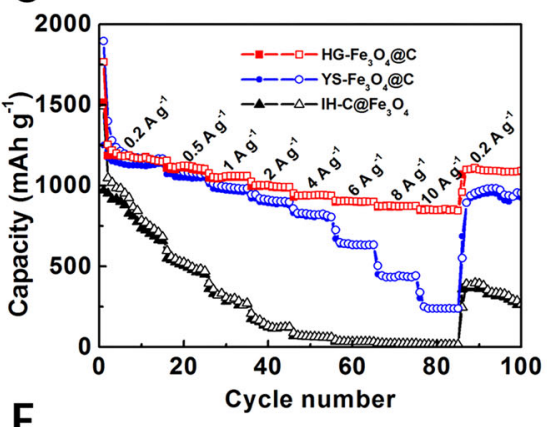

B

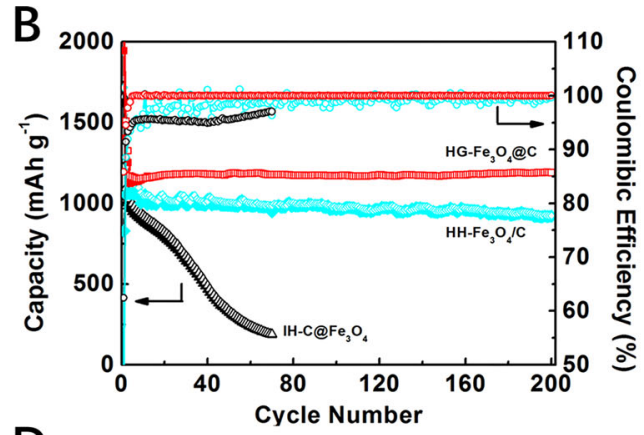

D

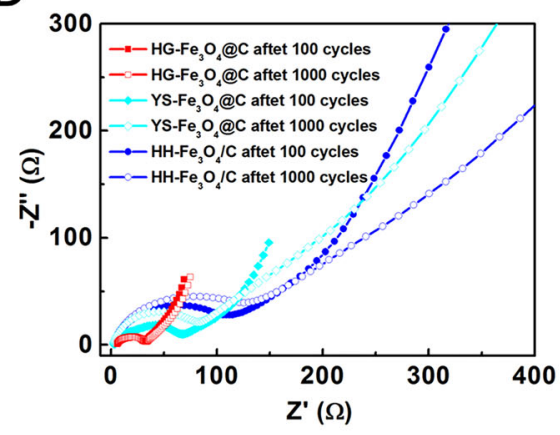

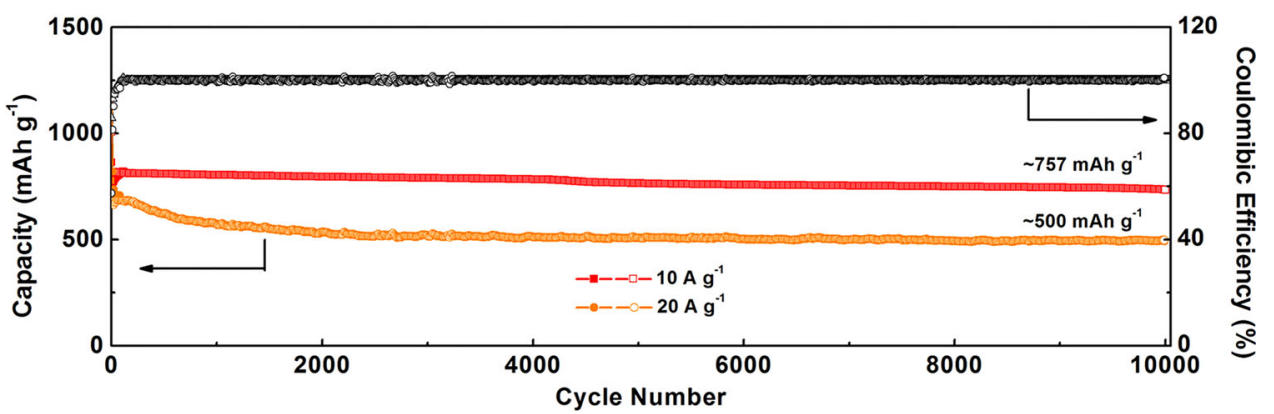

Fig. 3 Electrochemical characterizations of the hollow gradient-structured $\mathrm{Fe}_{3} \mathrm{O}_{\mathbf{4}} @ \mathrm{C}$ nanospheres $\left(\mathrm{HG}-\mathrm{Fe}_{3} \mathrm{O}_{4} @ \mathrm{C}\right.$ ) and the control samples application in lithium ion batteries. A Charge-discharge curves in the voltage range from 0.05 to $3.00 \mathrm{~V}$; $\mathbf{B}$ Cycling performances at a current density of $0.2 \mathrm{~A} \mathrm{~g}^{-1}$; C Rate performances at various current rates from 0.2 to $0.5,1,2,4,6,8,10 \mathrm{Ag}^{-1}$; D Nyquist plots between 100 to $0.05 \mathrm{kHz} ; \mathbf{E}$ Cycling performances under a high current density of 10 and $20 \mathrm{Ag}^{-1}$. Hollow hybrid $\mathrm{Fe}_{3} \mathrm{O}_{4} @ \mathrm{C}\left(\mathrm{HH}-\mathrm{Fe}_{3} \mathrm{O}_{4} / \mathrm{C}\right)$, yolk-shell $\mathrm{Fe}_{3} \mathrm{O}_{4} @ \mathrm{C}\left(\mathrm{YS}^{-} \mathrm{Fe}_{3} \mathrm{O}_{4} @ \mathrm{C}\right)$, and island-type C@Fe $3 \mathrm{O}_{4}(\mathrm{HI}-$ $\mathrm{C} @ \mathrm{Fe}_{3} \mathrm{O}_{4}$ ) nanospheres were prepared for comparison.

yolk-shell structures with hybrid gradient-structured shells and well-defined interior void spaces (Supplementary Fig. 15). We also show that the inorganic-organic competitive coating strategy can further be extended to prepare uniform $\mathrm{SiO}_{2} @ \mathrm{TiO}_{2} @ \mathrm{C}$ and $\mathrm{SiO}_{2} @ \mathrm{NiO} @ \mathrm{C}$ core-shell structures by using titanocene and nickelocene as the reactants, respectively (Supplementary Figs. 16, 17). Therefore, our coating method is versatile and robust for synthesizing core-shell and hollow structures with multiple functions and gradient-structured interface.

Electrochemical performance. The lithium-storage performances of the gradient-structured $\mathrm{Fe}_{3} \mathrm{O}_{4} @ \mathrm{C}$ nanospheres as an anode material were tested in the typical half-cell configuration. All capacity values reported here are based on the total mass of $\mathrm{Fe}_{3} \mathrm{O}_{4}$ and $\mathrm{C}$ in the nanospheres. The first three CV curves of the hollow gradient-structured $\mathrm{Fe}_{3} \mathrm{O}_{4} @ \mathrm{C}$ electrode at a scan rate of $0.2 \mathrm{mV} \mathrm{s}^{-1}$ from 0.0 and $3.0 \mathrm{~V}\left(\mathrm{vs} \mathrm{Li} / \mathrm{Li}^{+}\right.$) show a characteristic of typical metal oxide anodes (Supplementary Fig. 18). In the first cathodic scan, the broad reduction peak at $0.6 \mathrm{~V}$ can be assigned to the SEI formation and irreversible reactions, which disappear in the subsequent cycles. A connected wide peak in the anodic scan can be attributed to the oxidation of $\mathrm{Fe}^{0}$ to $\mathrm{Fe}^{3+}$. From the second cycle, two coupled redox peaks appeared in the $\mathrm{CV}$ curves, indicating the reversible electrochemical behavior of the gradient-structured $\mathrm{Fe}_{3} \mathrm{O}_{4} @ \mathrm{C}$ nanospheres. The charging and discharging curves of the gradientstructured $\mathrm{Fe}_{3} \mathrm{O}_{4} @ \mathrm{C}$ electrode (Fig. 3A) also exhibit typical electrochemical features of $\mathrm{Fe}_{3} \mathrm{O}_{4}$ anodes with a negligible change between the fifth and 50th cycles. The lithium-storage characteristic of gradient-structured $\mathrm{Fe}_{3} \mathrm{O}_{4} @ \mathrm{C}$ nanospheres were also tested at low current density of $0.1 \mathrm{C}\left(1 \mathrm{C}=926 \mathrm{~mA} \mathrm{~g}^{-1}\right.$, Supplementary Fig. 19). One clear declining plateau is observed in all discharging and charging curves, respectively, implying a wide potential window of the gradient-structured $\mathrm{Fe}_{3} \mathrm{O}_{4} @ \mathrm{C}$ nanospheres as a lithium ion battery anode.

To evaluate the structure-performance relationship, three commonly used anode without gradient-structures, including hollow hybrid $\mathrm{Fe}_{3} \mathrm{O}_{4} @ \mathrm{C}\left(\mathrm{HH}-\mathrm{Fe}_{3} \mathrm{O}_{4} / \mathrm{C}\right)$, yolk-shell $\mathrm{Fe}_{3} \mathrm{O}_{4} @ \mathrm{C}$ (YS$\left.\mathrm{Fe}_{3} \mathrm{O}_{4} @ \mathrm{C}\right)$, and hollow island-type $\mathrm{C} @ \mathrm{Fe}_{3} \mathrm{O}_{4}$ ( $\left.\mathrm{HI}-\mathrm{C} @ \mathrm{Fe}_{3} \mathrm{O}_{4}\right)$ nanospheres, were prepared for comparison (Supplementary Figs. 20,21). When charging and discharging in a low current density of $0.2 \mathrm{~A} \mathrm{~g}^{-1}$ (Fig. 3B), the gradient-structured $\mathrm{Fe}_{3} \mathrm{O}_{4} @ \mathrm{C}$ electrode demonstrates an excellent specific capacity of 1200 mAh g ${ }^{-1}$ with a Coulombic efficiency of $\sim 99.8 \%$, which is immensely higher than that of hollow island-type $\mathrm{C}_{0} \mathrm{Fe}_{3} \mathrm{O}_{4}(190$ mAh ${ }^{-1}$ ) and hollow hybrid $\mathrm{Fe}_{3} \mathrm{O}_{4} @ \mathrm{C}\left(990 \mathrm{mAh} \mathrm{g}^{-1}, 98.8 \%\right)$. 
Ex-situ TEM images (Supplementary Fig. 22) demonstrates the morphology of the typical hollow gradient-structured $\mathrm{Fe}_{3} \mathrm{O}_{4} @ \mathrm{C}$ nanosphere at different charging and discharging states during the fifth cycle. The diameter of the hollow nanosphere is about $415 \mathrm{~nm}$ at the beginning, and increased to 426 and $449 \mathrm{~nm}$ at the half and full discharging, respectively. In contrast, the corresponding void size decreases from 354 to 348 and $345 \mathrm{~nm}$ gradually for the buffering volumetric expansion. About $7 \%$ radial expansion of the gradient-structured $\mathrm{Fe}_{3} \mathrm{O}_{4} @ \mathrm{C}$ nanospheres can be evaluated from the full charging to full discharging state, which is very close to that of commercial graphite anode $(\sim 6 \%$ expansion in the direction perpendicular to the (002) crystal surface), and considerably lower than the theoretical value of $\mathrm{Fe}_{3} \mathrm{O}_{4}$ particles (80\% volume expansion, $\sim 22 \%$ radial expansion). When being charged, the structure dimension can be restored to its original state. Notably, the well-designed hollow gradientstructure can be perfectly retained at different states of charging and discharging, even after 100 or 10000 cycles at the different current densities of 0.2 or $10 \mathrm{~A} \mathrm{~g}^{-1}$ (Supplementary Figs. 23, 24).

As the current density increases from 0.2 to $0.5,1,2,4,6,8$, and $10 \mathrm{~A} \mathrm{~g}^{-1}$ for fast charging and discharging (Fig. 3C), the reversible capacities of the gradient-structured $\mathrm{Fe}_{3} \mathrm{O}_{4} @ \mathrm{C}$ electrode is decreased from 1200 to $1120,1060,990,940,900,870$, and 850 $\mathrm{mAh} \mathrm{g}^{-1}$, respectively. When the rate returns to $0.2 \mathrm{Ag}^{-1}$, the capacities of the gradient-structured $\mathrm{Fe}_{3} \mathrm{O}_{4} @ \mathrm{C}$ electrode comes back to $\sim 1180 \mathrm{mAh}^{-1}$, indicating an excellent rate reversibility based on the unique gradient-structure. As a comparison, the yolk-shell $\mathrm{Fe}_{3} \mathrm{O}_{4} @ \mathrm{C}$ electrode with a similar core-shell structure but without gradient $\mathrm{Fe}_{3} \mathrm{O}_{4}$ distribution can deliver comparable capacities with gradient-structured $\mathrm{Fe}_{3} \mathrm{O}_{4} @ \mathrm{C}$ at low current densities. However, when the current densities exceed $1 \mathrm{Ag}^{-1}$, it shows capacities of $990,910,820,630,430$, and $240 \mathrm{mAh} \mathrm{g}^{-1}$ at 1 , $2,4,6,8$, and $10 \mathrm{Ag}^{-1}$, respectively. In fact, the cycle life and capacities of the gradient-structured $\mathrm{Fe}_{3} \mathrm{O}_{4} @ \mathrm{C}$ nanospheres are much better than that of the previous works under ultrafast charge and discharge conditions (Supplementary Table 1). Importantly, the gradient-structured $\mathrm{Fe}_{3} \mathrm{O}_{4} @ \mathrm{C}$ electrode can stand stable for a long term under fast charging and discharging. After 10,000 cycles, it can deliver capacity as high as $\sim 750 \mathrm{mAh} \mathrm{g}^{-1}$ with a Coulombic efficiency closed to $99.0 \%$ at $10 \mathrm{Ag}^{-1}$ (Fig. 3E). This value is more than two times higher than that of the yolk-shell $\mathrm{Fe}_{3} \mathrm{O}_{4} @ \mathrm{C}$ (350 $\mathrm{mAhg}^{-1}$, Supplementary Fig. 25) and hollow hybrid $\mathrm{Fe}_{3} \mathrm{O}_{4} @ \mathrm{C}\left(330 \mathrm{mAhg} \mathrm{g}^{-1}\right.$, Supplementary Fig. 26) electrodes. Even at $20 \mathrm{Ag}^{-1}$, the capacities of the gradient-structured $\mathrm{Fe}_{3} \mathrm{O}_{4} @ \mathrm{C}$ electrode are still as high as $500 \mathrm{mAh} \mathrm{g}^{-1}$ after 10,000 cycles with a capacity fading $<0.003 \%$ per cycle, implying that our electrode can afford ultrafast charging and discharging for a long time. The ex-situ SEM images (Supplementary Fig. 27) show that thin, stable, and spatially confined SEI films are formed in the gradient-structured $\mathrm{Fe}_{3} \mathrm{O}_{4} @ \mathrm{C}$ electrode. All of the gradientstructured $\mathrm{Fe}_{3} \mathrm{O}_{4} @ \mathrm{C}$ nanospheres were retained intact very well on the surface of the electrode, indicating the excellent structural and thermal stability of gradient-structured $\mathrm{Fe}_{3} \mathrm{O}_{4} @ \mathrm{C}$ nanospheres. As a contrast, due to the constraints of the mass/charge transfer, a thicker SEI film is coagulated on the yolk-shell $\mathrm{Fe}_{3} \mathrm{O}_{4} @ \mathrm{C}$ electrode (Supplementary Fig. 28), which not only increases the interface resistance of the electrode but also leads to the fluctuating Coulombic efficiency (between 96.0 and 100.5\%) and inferior capacities. The morphology of the hollow hybrid $\mathrm{Fe}_{3} \mathrm{O}_{4} / \mathrm{C}\left(\mathrm{HH}-\mathrm{Fe}_{3} \mathrm{O}_{4} / \mathrm{C}\right)$ electrode is almost entirely damaged after 1000 cycles due to the spallation of SEI film caused by the large volume change of metal oxide $\mathrm{Fe}_{3} \mathrm{O}_{4}$ (Supplementary Fig. 29). Thus, the capacities of the hollow hybrid $\mathrm{Fe}_{3} \mathrm{O}_{4} @ \mathrm{C}-\mathrm{Fe}_{3} \mathrm{O}_{4} / \mathrm{C}$ electrode gradually fade from 650 to $330 \mathrm{mAh} \mathrm{g}^{-1}$ with low Coulombic efficiencies during 10,000 cycles. Those morphological changes can be further confirmed by the EIS results (Fig. 3D). The gradient-structured $\mathrm{Fe}_{3} \mathrm{O}_{4} @ \mathrm{C}$ electrode shows a constant interface resistance of $\sim 35 \Omega$ after 100 or 1000 cycles, which is much lower than that of the yolk-shell structured $\mathrm{Fe}_{3} \mathrm{O}_{4} @ \mathrm{C}(62 \Omega$ after 100 cycles and $83 \Omega$ after 1000 cycles) and the hollow hybrid $\mathrm{Fe}_{3} \mathrm{O}_{4} / \mathrm{C}$ (110 $\Omega$ after 100 cycles, and $135 \Omega$ after 1000 cycles). It further suggests that the gradient-structure is able to gradually release the stress caused by drastic volume change during fast charging and discharging.

Considering the fact that asymmetric charging and discharging are commonly applied in practical applications, it is important to evaluate the battery performances of the gradient-structured $\mathrm{Fe}_{3} \mathrm{O}_{4} @ \mathrm{C}$ electrodes at different charge and discharge current densities. When charging at $0.2 \mathrm{Ag}^{-1}$ and discharging at $10 \mathrm{Ag}^{-1}$, a high capacity of $\sim 900 \mathrm{mAhg}^{-1}$ and Coulombic efficiency of $\sim 97 \%$ can be obtained with negligible fading after 200 cycles. The result suggests that $\mathrm{Li}^{+}$diffusion thermodynamics and dynamics performances of at a high current are comparable with those at a low current in the solid phase (Supplementary Fig. 30). On the other hand, the cyclic stabilities of the gradient-structured $\mathrm{Fe}_{3} \mathrm{O}_{4} @ \mathrm{C}$ can be maintained well with high loading density at $10 \mathrm{~A} \mathrm{~g}^{-1}$. With the increasing, the mass loading to 5,10 , and $20 \mathrm{mg} / \mathrm{cm}^{2}$, the capacities of gradient-structured $\mathrm{Fe}_{3} \mathrm{O}_{4} @ \mathrm{C}$ nanospheres are decreasing to 727,635 , and $590 \mathrm{mAh} \mathrm{g}^{-1}$, respectively, based on the thickness increasing of the electrode (Supplementary Fig. 31).

\section{Discussion}

Inorganic-organic competitive coating strategy. We propose an inorganic-organic competitive coating and deposition process for the formation of the gradient-structured $\mathrm{Fe}_{3} \mathrm{O}_{4} @ \mathrm{C}$ shells (Fig. 4). At the beginning of the solvothermal reaction, the metallorganic ferrocene can be gradually hydrolyzed into iron ions and carbonaceous species by $\mathrm{H}_{2} \mathrm{O}_{2}$ (Fig. $4 \mathrm{~A}$ ). Then, the iron ions would be further hydrolyzed into Fe oxides and carbonaceous species could be polymerized into an amorphous carbon layer under the solvothermal condition (Fig. 4B). Thus, two competitive deposition reactions are occurred and much dependent on the thermodynamics for the controllable growth of unique gradientstructured $\mathrm{Fe}_{3} \mathrm{O}_{4} @ \mathrm{C}$ shells (Fig. 4C). At a relatively low temperature $\left(180^{\circ} \mathrm{C}\right)$, iron ions cannot fully be dissociated from coordination of both cyclopentadienes and hydrolyzed, thus iron oxide species cannot form under this condition. In contrast, some cyclopentadiene species partially decomposed from ferrocene can be polymerized into amorphous carbonaceous species, which can be coated on the surface of the colloidal $\mathrm{SiO}_{2}$ cores driven by the affinity interaction between the abundant $\mathrm{Si}-\mathrm{OH}$ groups and hydroxy/carboxyl groups. Thus, uniform $\mathrm{SiO}_{2} @ \mathrm{C}$ core-shell structures are obtained. Increasing the solvothermal temperature $\left(190^{\circ} \mathrm{C}\right)$ can slightly accelerate the polymerization reaction of carbonaceous species into a thicker layer. Moreover, the nucleation and growth of $\mathrm{Fe}_{3} \mathrm{O}_{4}$ nanoparticles can be triggered by the cross-linking and hydrolysis of iron ion species decomposed from ferrocene. Simultaneously, an ultrathin carbon layer is formed on the surface of $\mathrm{SiO}_{2} @ \mathrm{C}$ nanospheres, forming an island-like morphology. When applying a high solvothermal temperature $\left(200^{\circ} \mathrm{C}\right)$, the thermodynamics of the cross-linking, nucleation and growth of $\mathrm{Fe}_{3} \mathrm{O}_{4}$ nanocrystals is boosted, which is faster than that of the carbonaceous polymerization process. Therefore, $\mathrm{Fe}_{3} \mathrm{O}_{4}$ nanocrystals are first formed, then the amorphous carbonaceous species are coated on their surface due to the high surface energy of small nanocrystals, leading to the fast formation of $\mathrm{Fe}_{3} \mathrm{O}_{4} @ \mathrm{C}$ nanocrystals. Subsequently, the nanocrystals are self-assembled on the surface of colloidal $\mathrm{SiO}_{2}$ cores into the "reinforced concrete" inner layers to lower the total system energy. Furthermore, the amorphous carbonaceous layers are deposited outside with the exhaustion of iron species with 
A

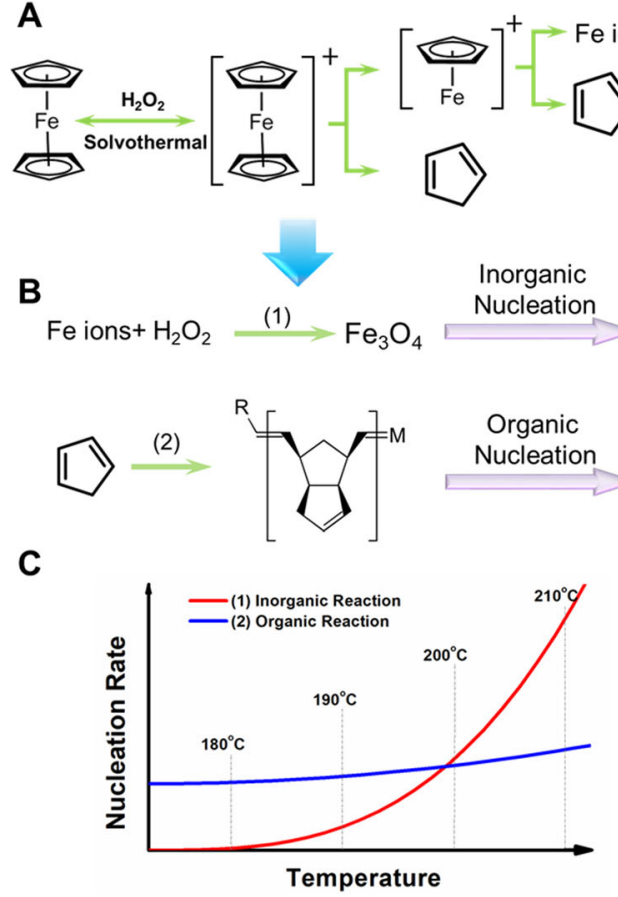

D
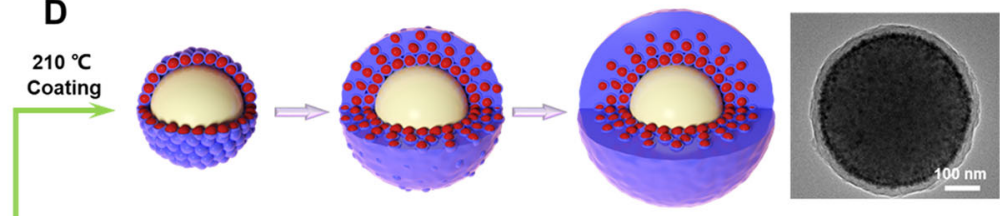

$200^{\circ} \mathrm{C}$ Coating
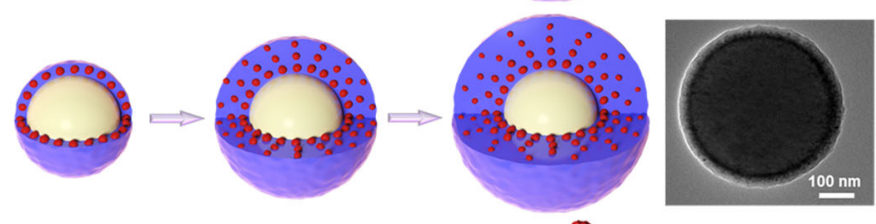

$190^{\circ} \mathrm{C}$

Coating
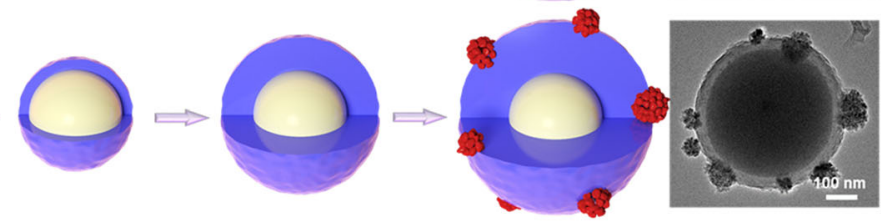

$180^{\circ} \mathrm{C}$

Coating
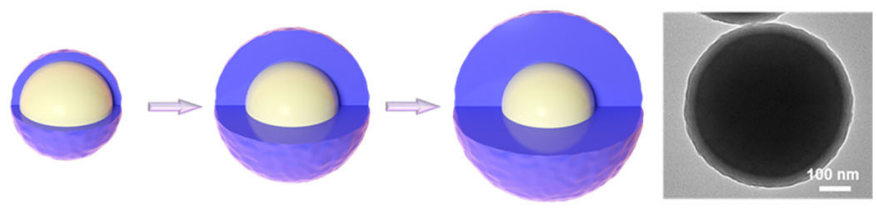

$\mathrm{SiO}_{2} \bullet \mathrm{Fe}_{3} \mathrm{O}_{4} \bullet$ Polymer Carbon

\section{Inorganic-Organic Competitive Coating Strategy}

Fig. 4 Schematic representation of the inorganic-organic competitive coating strategy. A The metallorganic ferrocene was gradually hydrolyzed into iron ions and cyclopentadienes; B Iron ions were further hydrolyzed into hydrated iron oxides (inorganic nucleation), and cyclopentadienes were oxidized and polymerized into amorphous carbonaceous species (organic nucleation); C Schematic diagram for nucleation rate between iron oxides and amorphous carbonaceous species; D Model diagram of competitive coating process by solvothermal reaction temperature of $210,200,190$, and $180^{\circ} \mathrm{C}$.

pallid domain of $\mathrm{Fe}_{3} \mathrm{O}_{4} @ \mathrm{C}$ nanocrystals, forming a gradient distribution coating-layer. Further increasing the temperature leads to the rapid nucleation and growth of $\mathrm{Fe}_{3} \mathrm{O}_{4}$ nanocrystals $\left(210^{\circ} \mathrm{C}\right)$. As a result, the most $\mathrm{Fe}_{3} \mathrm{O}_{4}$ nanocrystals are locally concentrated at the inner walls of the coating-layer. With the subsequent overgrowth of amorphous carbonaceous layers, the coconut-like gradient-structured $\mathrm{Fe}_{3} \mathrm{O}_{4} @ \mathrm{C}$ shells are eventually formed. Most of $\mathrm{Fe}_{3} \mathrm{O}_{4}$ nanoparticles with a size of $4-8 \mathrm{~nm}$ are aggregated into the inner layer $(\sim 10 \mathrm{~nm})$ and form a gradient high-to-low component distribution from inside to out $(15 \mathrm{~nm})$. Interestingly, after the carbonization at $600^{\circ} \mathrm{C}$, the carbon layer around the $\mathrm{Fe}_{3} \mathrm{O}_{4}$ nanoparticles can be easily graphitized due to the catalytic effect of iron ions, forming a graphitized carbon coating with few layers. In contrast, the thick carbon layer is still amorphous structures. Therefore, such inorganic-organic competitive coating strategy can be effectively applied to construct unique gradient-structure shells through well regulating the competitive reaction thermodynamics (Fig. 4D).

Structure activity relationship. One of the advantages of our gradient-structure is ensuring a sufficient "occlusion"-like contact between the active material and conductive shell, which can gradually relieve the stress concentration caused by drastic volume change, thus retaining the completeness and stability of the whole structure during ultrafast charging and discharging (Fig. 5). At the half discharge/charge state, the diameter of the gradient-structured $\mathrm{Fe}_{3} \mathrm{O}_{4} @ \mathrm{C}$ nanospheres increases by only about $2 \%$, indicating that the inner mesopores of the gradientstructure present a sustained-buffering effect on the drastic volume change of the active $\mathrm{Fe}_{3} \mathrm{O}_{4}$. Moreover, the gradientstructure gradually relies on the void space to alleviate the volume change in the following discharging process. About $7 \%$ of the diameter increase for the gradient-structured $\mathrm{Fe}_{3} \mathrm{O}_{4} @ \mathrm{C}$ nanospheres can be confirmed in comparison to the full charge and full discharge state, which is similar to the expansion coefficient of graphite anodes (6\%), and doesn't cause the burst of SEI film on the surface. Although a certain amount of volumetric energy density is sacrificed, the mass energy density is improved qualitatively. Thus, the morphology of SEI layer and the whole electrode can be retained after hundreds of cycles, suggesting an ultra-long life of the gradient-structured $\mathrm{Fe}_{3} \mathrm{O}_{4} @ \mathrm{C}$ eletrodes with the gradient-structure. In addition, the gradient-structure design affords other advantages for ultrafast and long-life performance (Fig. 5). In fact, each nanocrystallized $\mathrm{Fe}_{3} \mathrm{O}_{4}$ particle is conformably encapsulated by ultrathin graphitic carbon layers and then embedded in the inner wall of hollow carbon nanospheres, thus, resulting a very good ohm contact between active substance and modified conductive material. Furthermore, the ultrathin graphitic carbon layer ensures active particles independent of each other, thus prevent agglomeration of secondary particles during the charge and discharge cycling. As shown, even in full discharge state or after multiple cycles, $\mathrm{Fe}_{3} \mathrm{O}_{4}$ particles retain the initial encapsulated structure. Moreover, the inner active layer in the gradient-structure is encapsulated by an out amorphous carbon inactive layer, which enables SEI deposited on the outer surface of whole structures, thus spatially confined SEI formation (Supplementary Fig. 26).

In summary, we report an inorganic-organic competitive coating strategy for the synthesis of unique hollow gradientstructure of $\mathrm{Fe}_{3} \mathrm{O}_{4} @ \mathrm{C}$ nanospheres by using metalorganic compound ferrocene as a sole precursor. Using colloidal silica as a template, the competitive coating strategy can be achieved by one-step solvothermal reaction. The results show that the two 


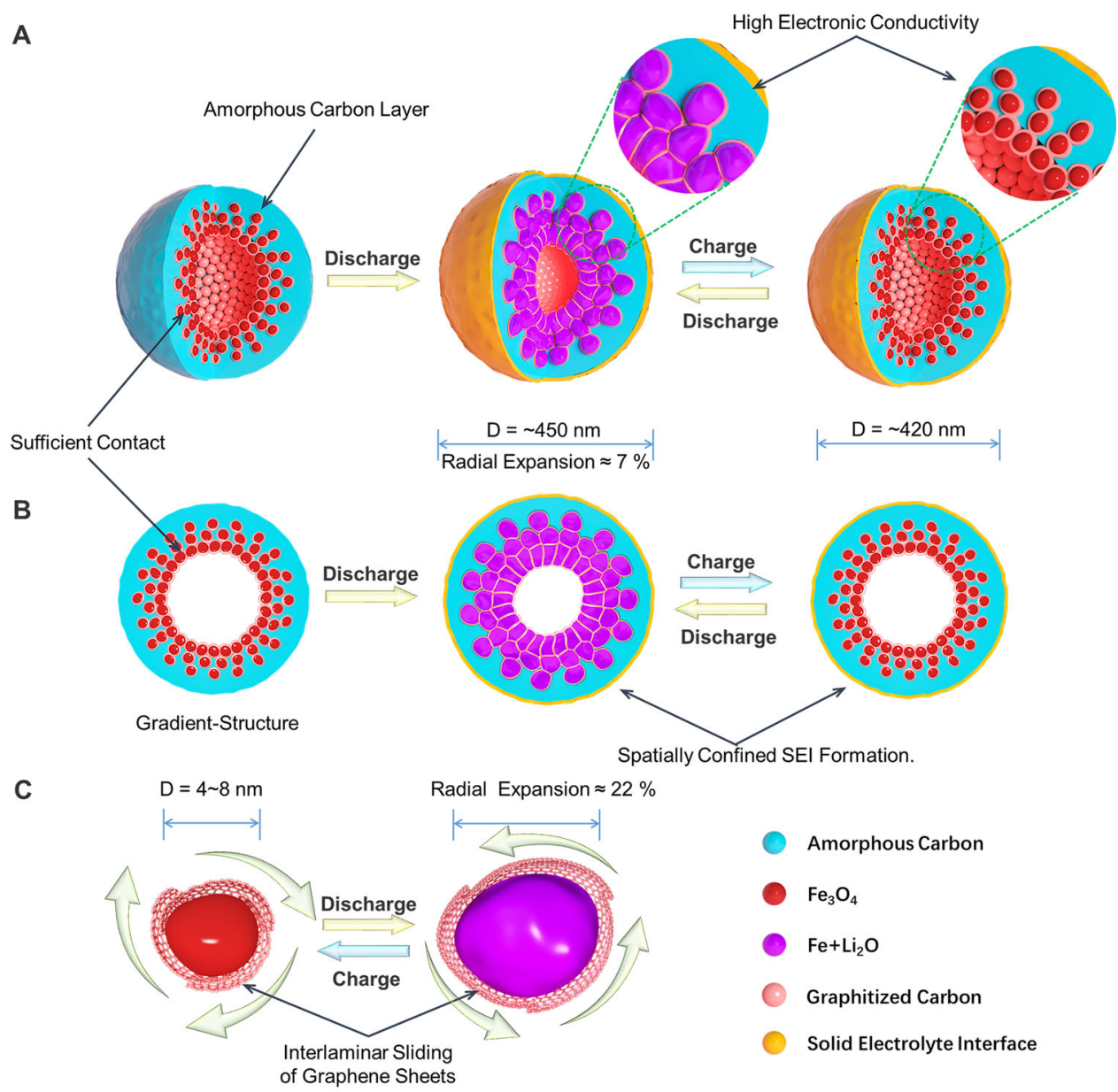

\section{Gradually Release the Stress by Drastic Volume Change}

Fig. 5 Schematic illustrations showing the structural change of the hollow gradient-structured $\mathrm{Fe}_{3} \mathrm{O}_{4} @ \mathrm{C}$ nanospheres during fast charging and discharging. A Three-dimensional (3D) view for the structural change of the hollow gradient-structured $\mathrm{Fe}_{3} \mathrm{O}_{4} @ \mathrm{C}$ nanospheres; B simplified 2D crosssection view for the structural change of the hollow gradient-structured $\mathrm{Fe}_{3} \mathrm{O}_{4} @ \mathbf{C}$ nanospheres; and $\mathbf{C}$ volume change of single $\mathrm{Fe}_{3} \mathrm{O}_{4}$ nanoparticle. $7 \%$ diameter expansion of the gradient-structured nanospheres can be evaluated from the full charging to full discharging state, which is considerably lower than the theoretical value of $\mathrm{Fe}_{3} \mathrm{O}_{4}$ particles $(22 \%)$. proving that the gradient-structure can gradually release the stress caused by the volume change.

competitive cross-linking and polymerization reactions between organic species and inorganic iron precursors from ferrocene can be effectively controlled by the thermodynamics for the formation of unique gradient-structured $\mathrm{Fe}_{3} \mathrm{O}_{4} @ \mathrm{C}$ shells. In fact, the metallorganic ferrocene can be gradually hydrolyzed into iron ions and cyclopentadienes by $\mathrm{H}_{2} \mathrm{O}_{2}$, then, iron ions could be further hydrolyzed and cross-linked into hydrated iron oxide species, and cyclopentadienes could be oxidized and polymerized into carbonaceous layer. As a typical hollow gradient-structured nanosphere, $\mathrm{Fe}_{3} \mathrm{O}_{4}$ nanoparticles $(4-8 \mathrm{~nm})$ conformably coated by ultrathin conductive graphitic carbon are aggregated into the inner layer with high-to-low component distribution from inside to out $(15 \mathrm{~nm})$, which is encapsulated by an amorphous carbon layer $(\sim 20 \mathrm{~nm})$. In fact, the particle size (from 150 to $500 \mathrm{~nm}$ ) and shell thicknesses (from 20 to $80 \mathrm{~nm}$ ) of the hollow gradientstructured nanospheres can be easily adjusted. We also show that this synthesis approach is versatile and can be easily extended to prepare other core-shell and hollow gradient structures, such as $\mathrm{SiO}_{2} @ v$ vid@G-Fe $\mathrm{O}_{4} @ \mathrm{C}, \mathrm{Fe}_{3} \mathrm{O}_{4} @$ void@G-Fe $\mathrm{O}_{4} @ \mathrm{C}, \mathrm{SiO}_{2} @ \mathrm{G}-$ $\mathrm{NiO} @ \mathrm{C}$, and $\mathrm{SiO}_{2} @ \mathrm{G}-\mathrm{TiO}_{2} @ \mathrm{C}$ nanospheres. When being used as an electrode, such unique gradient-structure can effectively relieve the stress concentration caused by drastic volume change, and demonstrate excellent stability during fast charging and discharging. As a result, the hollow gradient-structured $\mathrm{Fe}_{3} \mathrm{O}_{4} @ \mathrm{C}$ nanospheres exhibit a highly reversible capacity of $\sim 750 \mathrm{mAh} \mathrm{g}^{-1}$ after 10,000 cycles at a high current density of $10 \mathrm{Ag}^{-1}$, which is more than twice as high as that of the well-known yolk-shell (350 $\left.\mathrm{mAh}^{-1}\right)$ and hollow hybrid structure $\left(330 \mathrm{mAh}^{-1}\right)$ anodes. Even at the current density as high as $20 \mathrm{~A} \mathrm{~g}^{-1}$, the capacity of the gradient-structured $\mathrm{Fe}_{3} \mathrm{O}_{4} @ \mathrm{C}$ electrode is still as high as $500 \mathrm{mAh}$ $\mathrm{g}^{-1}$ during 10,000 cycles with a capacity fading of $<0.003 \%$ per cycle. More importantly, the gradient-structured $\mathrm{Fe}_{3} \mathrm{O}_{4} @ \mathrm{C}$ electrode retains stable capacities of about $\sim 900 \mathrm{mAhg}^{-1}$ even when asymmetric charge and discharge (discharge at $10 \mathrm{Ag}^{-1}$, charge at $\left.0.2 \mathrm{~A} \mathrm{~g}^{-1}\right)$. We believe that the gradient-structure will bring a revolution in the field of ultrafast charge and discharge for LIBs. The inorganic-organic competitive coating strategy paves a way for the design and synthesis of core-shell and hollow structured materials for energy storage.

\section{Methods}

Synthesis of materials. The hollow gradient-structured $\mathrm{Fe}_{3} \mathrm{O}_{4} @ \mathrm{C}\left(\mathrm{HG}-\mathrm{Fe}_{3} \mathrm{O}_{4} @ \mathrm{C}\right)$ nanospheres were prepared by the inorganic-organic competitive coating strategy. Uniform colloidal $\mathrm{SiO}_{2}$ nanospheres with a particle size of $\sim 350 \mathrm{~nm}$ were synthesized and selected as a template core (Supplementary Fig. 1a, b). In a typical process, $0.20 \mathrm{~g}$ of the colloidal $\mathrm{SiO}_{2}$ nanospheres and $0.40 \mathrm{~g}$ of metallorgaonic compound ferrocene were added into $25 \mathrm{~mL}$ of acetone with stirring for $10 \mathrm{~min}$. 
Next, $2.0 \mathrm{~mL}$ of hydrogen peroxide $\left(\mathrm{H}_{2} \mathrm{O}_{2}\right)$ solution $(25 \%)$ was added into the mixture. After continually stirring for $30 \mathrm{~min}$, the mixture was transferred into an autoclave and heated at $210^{\circ} \mathrm{C}$ for $24 \mathrm{~h}$. The products were collected by centrifugation and washed with ethanol for three times, then and dried at room temperature. The as-made samples were calcined at $600^{\circ} \mathrm{C}$ in $\mathrm{N}_{2}$ atmosphere for 1 h. Finally, the gradient-structured $\mathrm{Fe}_{3} \mathrm{O}_{4} @ \mathrm{C}$ nanospheres were obtained by removing the colloidal $\mathrm{SiO}_{2}$ cores with $1.0 \mathrm{M} \mathrm{NaOH}$ aqueous solution.

The inorganic-organic competitive coating strategy could be extended to prepare uniform gradient-structured $\mathrm{TiO}_{2} @ \mathrm{C}$ and $\mathrm{NiO} @ \mathrm{C}$ layers. In a typical process for the gradient-structured $\mathrm{TiO}_{2} @ \mathrm{C}$ layer, $0.20 \mathrm{~g}$ of the colloidal $\mathrm{SiO}_{2}$ nanospheres and $0.25 \mathrm{~g}$ of titanocene were added into $25 \mathrm{~mL}$ of acetone with stirring for $10 \mathrm{~min}$. Next, $0.20 \mathrm{~mL}$ of hydrogen peroxide solution (25\%) was added into the mixture. After continually stirring for $30 \mathrm{~min}$, the mixture was transferred into an autoclave and heated at $150^{\circ} \mathrm{C}$ for $24 \mathrm{~h}$. The products were collected by centrifugation and washed with ethanol for three times, then and dried at room temperature. In a typical process for the gradient-structured $\mathrm{NiO} @ \mathrm{C}$ layer, $0.20 \mathrm{~g}$ of the colloidal $\mathrm{SiO}_{2}$ and $0.15 \mathrm{~g}$ of nickelocene were added into $25 \mathrm{~mL}$ of acetone with stirring for $10 \mathrm{~min}$. Next, $0.10 \mathrm{~mL}$ of hydrogen peroxide solution (25\%) was added into the mixture. After continually stirring for $30 \mathrm{~min}$, the mixture was transferred into an autoclave and heated at $120^{\circ} \mathrm{C}$ for $24 \mathrm{~h}$. The products were collected by centrifugation and washed with ethanol for three times, then and dried at room temperature.

Characterizations. The morphologies of the samples were investigated by using FESEM (Zeiss Supra 4VP) and transmission electron microscopy (TEM, JEOL JEM-ARM200F, with acceleration voltage of $200 \mathrm{keV}$ ). The samples for TEM measurements were suspended in ethanol and supported onto a holey carbon film on a $\mathrm{Cu}$ gird. FESEM images were taken on a Hitachi S-4800 microscope. The crystalline microstructures of samples were characterized by using XRD diffractometer (Bruker D8 diffractometer) with a $\mathrm{Cu} \mathrm{Ka}$ radiation source $(\lambda=$ $0.15406 \mathrm{~nm}$ ). $\mathrm{N}_{2}$ adsorption-desorption isotherms were recorded on a Micromeritics 3Flex analyzer at the temperature of $77 \mathrm{~K}$. The samples were degassed in a vacuum at $150^{\circ} \mathrm{C}$ for $6 \mathrm{~h}$ and the Brunauer-Emmett-Teller (BET) method was utilized to calculate the specific surface areas and pore size. The micropore volumes were determined from Dubinin-Radushkevich (DR) equation with both $\mathrm{N}_{2}$ adsorption at $77 \mathrm{~K}$ and $\mathrm{CO}_{2}$ adsorption at $273 \mathrm{~K}$. The total pore volume was determined from the $\mathrm{N}_{2}$ adsorbed amount at $\mathrm{P} / \mathrm{P}_{0}=0.99$ according to the Gurvitch rule. Thermogravimetric analysis (TGA) curves were acquired on a STA $449 \mathrm{C}$ thermobalance with a temperature ramp of $10^{\circ} \mathrm{C} \mathrm{min}^{-1}$.

Cell assembly and electrochemical measurements. Electrochemical measurements were carried out in 2016 type button cells with pure lithium foil as both counter and reference electrode. The active materials (for example, the hollow gradient-structured $\mathrm{Fe}_{3} \mathrm{O}_{4} @ \mathrm{C}$ nanospheres) were mixed with the binder (poly (vinylidene fluoride)) and conductive agent (acetylene black) at a weight ratio of 8:1:1 to form a slurry. The mixing slurry was homogeneously pasted on nickel foam and dried in a vacuum oven at $80^{\circ} \mathrm{C}$ for $12 \mathrm{~h}$. After a hot- $\left(90^{\circ} \mathrm{C}, 30 \mathrm{Mpa}\right)$ and cold-pressing $\left(30^{\circ} \mathrm{C}, 50 \mathrm{Mpa}\right)$, the as-prepared electrodes were used to assemble the battery. The different areal mass loading of $1,5,10$, and $20 \mathrm{mg} / \mathrm{cm}^{2}$ was fabricated to investigate the lithium storage performance of gradient-structured $\mathrm{Fe}_{3} \mathrm{O}_{4} @ \mathrm{C}\left(\mathrm{HG}-\mathrm{Fe}_{3} \mathrm{O}_{4} @ \mathrm{C}\right)$ nanospheres. The electrolyte was composed of $1 \mathrm{M}$ $\mathrm{LiPF}_{6}$ in a 1:1:1 of ethylene carbonate (EC), diethyl carbonate (DEC), and dimethyl carbonate (DMC). Charge-discharge measurements were performed on a LAND CT2001A multichannel battery testing system within a voltage window of 0.05-3.0 V. Cyclic voltammetry (CV) measurements were carried out on a $\mathrm{CHI} 660 \mathrm{E}$ electrochemical workstation at a sweep rate of $0.2 \mathrm{mV} \mathrm{s}^{-1}$ within a voltage range of $0.0-3.0 \mathrm{~V}$.

\section{Data availability}

Data supporting the findings of this study are available within the article and the associated Supplementary Information Section. Any other data are available from the corresponding authors upon reasonable request. The source data underlying Fig. 3 and Supplementary Figs. are provided as a Source Data file.

Received: 4 August 2020; Accepted: 20 January 2021; Published online: 20 May 2021

\section{References}

1. Dunn, B., Kamath, H. \& Tarascon, J.-M. Electrical energy storage for the grid: a battery of choices. Science 334, 928-935 (2011).

2. Nishide, H. \& Oyaizu, K. Toward flexible batteries. Science 319, 737-738 (2008).

3. Dong, X. et al. Environmentally-friendly aqueous $\mathrm{Li}$ (or Na)-ion battery with fast electrode kinetics and super-long life. Sci. Adv. 2, e1501038 (2016).
4. Lu, J. et al. The role of nanotechnology in the development of battery materials for electric vehicles. Nat. Nanotechnol. 11, 1031-1038 (2016).

5. Kühne, M. et al. Ultrafast lithium diffusion in bilayer graphene. Nat. Nanotechnol. 12, 895-900 (2017).

6. Sun, H. et al. High-rate lithiation-induced reactivation of mesoporous hollow nanospheres for long-lived lithium-ion batteries. Nat. Commun. 5, 4526 (2014).

7. Li, Y. et al. Growth of conformal graphene cages on micrometre-sized silicon particles as stable battery anodes. Nat. Energy 1, 15029 (2016).

8. Liu, N. et al. A pomegranate-inspired nanoscale design for large-volumechange lithium battery anodes. Nat. Nanotechnol. 9, 187-192 (2014).

9. Lu, Y., Yu, L. \& Lou, X. Nanostructured conversion-type anode materials for advanced lithium-ion batteries. Chem 4, 1-25 (2018).

10. Zhang, H. et al. Electroplating lithium transition metal oxides. Sci. Adv. 3, e1602427 (2017).

11. Chan, C. K. et al. High-performance lithium battery anodes using silicon nanowires. Nat. Nanotechnol. 3, 31-35 (2008).

12. Ryu, J. et al. Mechanical mismatch-driven rippling in carbon-coated silicon sheets for stress-resilient battery anodes. Nat. Commun. 9, 2924 (2018).

13. Griffith, K. J., Wiaderek, K. M., Gibin, G., Marbella, L. E. \& Grey, C. P. Niobium tungsten oxides for high-rate lithium-ion energy storage. Nature 559, 556-563 (2018).

14. Rehnlund, D. et al. Lithium trapping in alloy forming electrodes and current collectors for lithium based batteries. Energy Environ. Sci. 10, 1350-1357 (2017).

15. Jung, S. et al. Lithium-free transition metal monoxides for positive electrodes in lithium-ion batteries. Nat. Energy 2, 16208 (2017).

16. Zhang, W. et al. Localized concentration reversal of lithium during intercalation into nanoparticles. Sci. Adv. 4, eaao2608 (2018).

17. Dargel, V. et al. In situ real-time gravimetric and viscoelastic probing of surface films formation on lithium batteries electrodes. Nat. Commun. 8, 1389 (2017).

18. Jin, Y. et al. Self-healing SEI enables full-cell cycling of a silicon-majority anode with a coulombic efficiency exceeding 99.9\%. Energy Environ. Sci. 10, 580-592 (2017).

19. Lu, Z. et al. Nonfilling carbon coating of porous silicon micrometer-sized particles for high-performance lithium battery anodes. ACS Nano $\mathbf{9}$, 2540-2547 (2015)

20. Bresser, D., Passerini, S. \& Scrosati, B. Leveraging valuable synergies by combining alloying and conversion for lithium-ion anodes. Energy Environ. Sci. 9, 3348-3367 (2016).

21. Guan, B., Yu, L., Li, J. \& Lou, X. A universal cooperative assembly-directed method for coating of mesoporous $\mathrm{TiO}_{2}$ nanoshells with enhanced lithium storage properties. Sci. Adv. 2, e1501554 (2016).

22. Chen, Y., Yu, X., Li, Z., Paik, U. \& Lou, X. Hierarchical $\mathrm{MoS}_{2}$ tubular structures internally wired by carbon nanotubes as a highly stable anode material for lithium-ion batteries. Sci. Adv. 2, e1600021 (2016).

23. Lu, Y., Nai, J. \& Lou, X. Formation of $\mathrm{NiCo}_{2} \mathrm{~V}_{2} \mathrm{O}_{8}$ yolk-double shell nanospheres with enhanced lithium storage properties. Angew. Chem. Int. Ed. 57, 2899-2903 (2018).

24. Sun, H. et al. Three-dimensional holey-graphene/niobia composite architectures for ultrahigh-rate energy storage. Science 356, 599-604 (2017)

25. Wang, J. et al. Multi-shelled metal oxides prepared via an anion-adsorption mechanism for lithium-ion batteries. Nat. Energy 1, 16050 (2016).

26. Hua, X. et al. Lithiation thermodynamics and kinetics of the TiO2 (B) nanoparticles. J. Am. Chem. Soc. 139, 13330-13341 (2017).

27. Tabassum, H. et al. A universal strategy for hollow metal oxide nanoparticles encapsulated into $\mathrm{B} / \mathrm{N}$ Co-doped graphitic nanotubes as high-performance lithium-ion battery anodes. Adv. Mater. 30, 1705441 (2018).

28. Chang, W. et al. Controlling electric potential to inhibit solidelectrolyte interphase formation on nanowire anodes for ultrafast lithium-ion batteries. Nat. Commun. 9, 3461 (2018).

29. Xiao, Q. et al. Inward lithium-ion breathing of hierarchically porous silicon anodes. Nat. Commun. 6, 8844 (2015)

30. He, Y. et al. Ultrathin Li4Ti5O12 nanosheet based hierarchical microspheres for high-rate and long-cycle life li-ion batteries. Adv. Energy Mater. 7, 1700950 (2017).

31. $\mathrm{Li}, \mathrm{W}$. et al. General strategy to synthesize uniform mesoporous $\mathrm{TiO}_{2} /$ graphene/mesoporous $\mathrm{TiO}_{2}$ sandwich-like nanosheets for highly reversible lithium storage. Nano Lett. 15, 2186-2193 (2015).

32. Shon, J. et al. Discovery of abnormal lithium-storage sites in molybdenum dioxide electrodes. Nat. Commun. 7, 11049 (2016).

33. Li, S., Chen, J., Gong, X., Wang, J. \& Lee, P. Holey graphene-wrapped porous $\mathrm{TiNb}_{24} \mathrm{O}_{62}$ microparticles as high performance intercalation pseudocapacitive anode materials for lithium-ion capacitors. NPG Asia Mater. 10, 406-416 (2018).

34. Hwang, S. et al. A case study on fibrous porous $\mathrm{SnO}_{2}$ anode for robust, highcapacity lithium-ion batteries. Nano Energy 10, 53-62 (2014). 
35. Wang, Z., Zhou, L. \& Lou, X. Metal oxide hollow nanostructures for lithiumion batteries. Adv. Mater. 24, 1903-1911 (2012).

36. Liu, H., Li, W., Shen, D., Zhao, D. \& Wang, G. Graphitic carbon conformal coating of mesoporous $\mathrm{TiO}_{2}$ hollow nanospheres for high-performance lithium ion battery anodes. J. Am. Chem. Soc. 137, 13161-13166 (2015).

37. Liu, B. et al. Extraordinary pseudocapacitive energy storage triggered by phase transformation in hierarchical vanadium oxides. Nat. Commun. 9, 1375 (2018).

38. Odziomek, M. et al. Hierarchically structured lithium titanate for ultrafast charging in long-life high capacity batteries. Nat. Commun. 8, 15636 (2017).

39. Lee, J. et al. Everlasting living and breathing Gyroid 3D Network in Si@SiOx/ C nanoarchitecture for lithium ion battery. ACS Nano 13, 9607-9619 (2019).

40. Chae, S., Ko, M., Kim, K., Ahn, K. \& Cho, J. Confronting issues of the practical implementation of Si anode in high-energy lithium-ion batteries. Joule $\mathbf{1}$, 47-60 (2017).

41. Yao, X. \& Zhao, Y. Three-dimensional porous graphene networks and hybrids for lithium-ion batteries and supercapacitors. Chem 2, 171-200 (2017).

42. Li, M. et al. Scalable dry production process of a superior 3D net-like carbon based iron oxide anode material for lithium-ion batteries. Angew. Chem. Int. Ed. 56, 12649-12653 (2017).

\section{Acknowledgements}

This work was supported by the National Key R\&D Program of China (2018YFA0209401, 2018YFE0201701, and 2017YFA0207303), and the National Natural Science Foundation of China (21975050 and 21733003), the Key Basic Research Program of Science and Technology Commission of Shanghai Municipality (17JC1400100).

\section{Author contributions}

D.Z., W.L., and Y.X. contributed to the conception and design of the experiments, analysis of the data and writing the manuscript. T.Z., X.Z., Y.Z., H.H., C.H., X.Z., Y.C., X.T., and J.W. assisted Y.X. for the synthesis of materials and the data collection and analysis. All authors contributed to the discussion and manuscript preparation.

\section{Competing interests}

The authors declare no competing interests.

\section{Additional information}

Supplementary information The online version contains supplementary material available at https://doi.org/10.1038/s41467-021-23150-8.

Correspondence and requests for materials should be addressed to W.L. or D.Z.

Peer review information Nature Communications thanks the anonymous reviewer(s) for their contribution to the peer review of this work. Peer reviewer reports are available.

Reprints and permission information is available at http://www.nature.com/reprints

Publisher's note Springer Nature remains neutral with regard to jurisdictional claims in published maps and institutional affiliations.

(c) (i) Open Access This article is licensed under a Creative Commons Attribution 4.0 International License, which permits use, sharing, adaptation, distribution and reproduction in any medium or format, as long as you give appropriate credit to the original author(s) and the source, provide a link to the Creative Commons license, and indicate if changes were made. The images or other third party material in this article are included in the article's Creative Commons license, unless indicated otherwise in a credit line to the material. If material is not included in the article's Creative Commons license and your intended use is not permitted by statutory regulation or exceeds the permitted use, you will need to obtain permission directly from the copyright holder. To view a copy of this license, visit http://creativecommons.org/ licenses/by/4.0/.

(C) The Author(s) 2021 